\title{
American Undergraduate Students' Experiences in Conversational Partnerships with Chinese International Students
}

\author{
Takahiro Sato \\ University of Tsukuba, Japan \\ Ryan Miller \\ Kent State University, USA
}

\begin{abstract}
The purpose of the current study was to describe American domestic students' experiences interacting with international students in a conversation partner program at an American university. This study used in-depth, semi-structured interviews grounded in positioning theory. Seven American students (three men and four women) participated. They served as conversation partners of Chinese international exchange students every fall semester. Four major interrelated themes emerged from the data. They were (a) seeking strategies for overcoming intercultural communication challenges, (b) addressing challenges for explaining sarcasm concepts, (c) finding mutual hobbies and interests, and (d) integrating field trips into the conversational program. This study encourages academic departments and faculty to develop a study group of conversational partnerships associated with value, origins, languages, and cultures of international students. This will contribute to a greater appreciation of the richness of diversity and to meaningful academic and social experiences at American universities for all students.
\end{abstract}

Keywords: conversational partnerships, international students, positioning, sarcasm language 


\section{INTRODUCTION}

International students increasingly play an important role in the vibrant diversity of college and university campuses in the United States (Sato \& Hodge, 2015a). According to the Open Doors Report on International Exchange (Institute of International Education, 2019), over 1 million international students are enrolled in American colleges and universities, and international students contribute over $\$ 44$ billion to the U.S. economy through tuition, room and board, and other expenses. More specifically, students from China are the largest group of international students, with nearly 370,000 Chinese undergraduate and graduate students studying in U.S. higher education during the 2018-2019 academic year, representing over a third of all international students in the United States (Institute of International Education, 2019).

Although there are many social and academic benefits of campus internationalization that are facilitated by interaction between international and domestic students (Welikala \& Watkins, 2008), several researchers have reported a number of challenges in facilitating this interaction. American students may harbor negative stereotypes, which may result in social avoidance (Arkoudis et al., 2012; Spencer-Rodgers, 2001). American domestic students have been found to perceive international students as maladjusted, naive, and confused about American customs, social practices, and the U.S. educational system (Leong \& Chou, 1996). Language and cultural barriers can lead to interaction challenges and to the perception by domestic students that international students are socially inhibited, withdrawn, or insular (Pedersen, 1991). Moreover, international students' friendship patterns may contribute to American students' perceptions of international students as cold, distant, and clannish (Pedersen, 1991).

Wilson (1993) suggested that students benefit from conversational partnership programs that help both American and international students gain substantive knowledge and perceptual understanding of a global perspective and develop interpersonal relationships. Through such programs, American students can also expand their cultural knowledge and development of intercultural relationships. The purpose of conversational partnership programs is to pair students and ask them to meet weekly within the academic year to discuss communication concepts and other topics of mutual interest (Wilson, 1993). Much of the previous research on conversation partner programs has focused on the experiences of international students or language learners (e.g., Abe et al., 1998; Nishioka, 2014; Ursell, 2014), rather than the experiences of domestic students. However, the experiences of international and domestic students in conversation partner programs can be quite different. For example, E. J. Lee (2016) found that international students benefitted from a conversation partner program in terms of linguistic development, while domestic students benefitted in terms of cultural exchange. Other research on conversation partner programs has focused on ways to help international students understand American universities (e.g., Chang, 2011) or to structure and facilitate conversation partner programs (e.g., Aaron et al., 2018; Geary, 2016; Spitzman \& Waugh, 2018; Thomas et al., 2018). Little research has focused specifically on describing and explaining 
American domestic students' experiences in conversation partner programs with Chinese international students. Examining the experiences of American domestic students is an important endeavor in a time of increasing international student diversity at U.S. educational institutions to better understand and improve their experiences as academic supporters. The purpose of the current study was to describe and explain American domestic students' experiences interacting with nonnative English-speaking international students as part of a conversational partnership at an American university. Two research questions guided this study: (a) How interested are American students in learning and understanding the ways international students think, behave, and speak? (b) How do American students overcome challenges in communication with international students during conversation?

\section{LITERATURE REVIEW}

Research on American students' stereotypes of Chinese international students specifically has shown that American students may perceive Chinese international students as having poor English-speaking skills, only being friends with Chinese students, not being interested in American culture, being socially awkward, and being either quiet and shy or loud and annoying (Ruble \& Zhang, 2013). While these are stereotypes (rather than factual truth), they may nonetheless create challenges in communication between American domestic students and Chinese international students. These challenges exist despite the fact that international students generally, and Chinese students specifically, are highly talented individuals who are hardworking, intelligent, determined, and eager to learn from their experiences in the United States (Leong \& Chou, 1996; Spencer-Rodgers, 2001).

Several studies have focused on social interaction between international and domestic students as an important arena for developing students' cognitive abilities (Ryan \& Hellmundt, 2005; Sheets, 2005) and creating opportunities for learning (Ryan \& Viete, 2009). Through interactions with people from different linguistic and cultural backgrounds, people realize how their own perceptions, assumptions, values, and general understanding of the world differ from those of others (Arkoudis et al., 2012). Luo and Jamieson-Drake (2013) conducted a survey of 5,676 alumni of four American universities to investigate the influence of interaction with international students on college outcomes among domestic students. They found that American students who engaged with international students, in any format, were more likely to question their own beliefs and values, and that such questioning was related to greater skill development, intellectual development, and leadership skills. In a study of a peer-mentoring program, Geelhoed et al. (2003) found domestic students who interacted with international students showed increased cross-cultural awareness and sensitivity.

A number of studies have made recommendations about how to best facilitate interaction between international and domestic students. Thomas et al. (2018) found leveraging common ground (e.g., cultural celebrations, faith, common experiences, challenges) can lead to positive outcomes when it comes to mutual 
interaction and cross-cultural learning. Aaron et al. (2018) presented recommendations for student-coordinated conversation partner programs. They suggested recruiting domestic students from student leadership organizations, developing a partner-matching program, and offering certificates of ambassadorship to domestic and international students (who attended at least four sessions). Through these experiences, their conversation partnership program promoted student-centered learning that encouraged positive changes in domestic and international students' communication skills, cultural knowledge, and relationship development (Aaron et al., 2018).

In the past decade, there has been an increase in studies that explored Chinese international students' acculturative patterns (e.g., Cheng \& Erben, 2012), crosscultural experiences of Chinese international students who studied in the United S (e.g., Batterton \& Horner, 2016; J. J. Lee \& Rice, 2007), and media and internet usage and habits in the United States (Li \& Chen, 2014). These studies have explained various types of academic and social challenges, culture shock, and adjustments during study abroad. In a synthesis of research on Chinese international students' experiences in American institutions of higher education, Zhang-Wu (2018) found that the experiences of Chinese international students may be different from those of other students.

Particularly relevant to the present study are culturally based communication patterns that may affect communication between American and Chinese students. The United States has been described as a "low-context" culture, while China is considered a "high-context" culture (D. Kim et al., 1998). In a low-context culture, communication between people is made more explicit and nonpersonal, new information is more easily introduced, and confrontation and open disagreement is more acceptable. In a high-context culture, on the other hand, communication depends more on the physical or social context, and less information is conveyed in the verbalized portion of the message. In high context cultures, such as China, direct confrontation is avoided in order to maintain social harmony and to save face, leading to more indirect communication (D. Kim et al., 1998).

\section{CONCEPTUAL FRAMEWORK}

The current study was grounded in positioning theory (Harré \& van Langenhove, 1999). This is a theory of social behavior that explains the fluid patterns of dynamic and changing rights and duties among groups of social actors (Varela \& Harré, 1996). The term "positioning" means to analyze interpersonal encounters from a discursive viewpoint (Hollway, 1984). This framework allows researchers to explore the capacity of American conversation partners to position themselves and, in this case, to describe how they negotiate and implement English-speaking practices with international university students who use English as a second language. Relationships with international university students are operationalized in the current study as getting along well with and being liked by their peers. High quality interactions with peers are associated with both academic and nonacademic outcomes among college students (Hamm \& Zhang, 2010; Ladd et 
al., 2009), including engagement (Buhs, 2005), perceived communication competence (Buhs, 2005), and social support. Positioning theory helps us better understand and explain what American conversation partners might or might not do based on their experiences, which influences their thoughts, feelings, and perceptions about interacting with international students.

One perspective of positioning theory is intentional self-positioning, which incorporates both a conceptual repertoire and a location for persons within the structure of rights and duties (Yoon, 2008). Hermans (2001) identified two factors that affect an individual's position to manage the environment and time- - that is, internal and external factors of self-positioning. An internal factor refers to a position within the inner group that the individual feels is part of themself (e.g., I as a native speaker, I as an American). An external factor refers to a position within the outer group (e.g., my group of international students). Both internal and external factors are considered self-positions, because they are part of a self that is intrinsically or extrinsically extended to the group environment and culture that responds to individual experiences in the environment that is perceived as 'mine' (Hermans, 2001). Self-positions identify the complex shifts between internal and external factors that help to describe an individual's professionalism, social behaviors, and challenges in a variety of meanings in interaction (Hermans, 2001).

Davies and Harré (1990) used the term "reflective positioning," which is useful in explaining how American conversation partners position their own roles as conversational mentors. The term "reflexivity" refers to how conversation partners critically monitor and understand the role of the self in interactions. Reflective positioning is closely related to the personal interpretative framework (in particular, conversational task perception) or the normative assumptions about good communication that are the basis on which individuals ground their decisions for actions in particular situations (Vanassche \& Kelchtermans, 2014). Conversation partners' reflective positions shape how they perform their roles, responsibilities, and duties (Yoon, 2008). For example, the conversation partners might use patterns of reflection that negotiate themselves and international students in their conversation sessions (Jones, 1997). Because conversation partners participate in diverse discourses, they must combine different positions (e.g., roles as friends, facilitators, mentors, or helpers; Jones, 1997). Although they might consciously understand that they play various roles when working with international students, the domestic students might unintentionally position such students as powerless learners in isolated spaces, which can lead to negative consequences such as marginalizing (Yoon, 2008). Jones (1997) explained that it is important that conversation partners analyze and reflect on their own disposition as opposed to or aligned with other positioning in conversation sessions.

Conversation partners' reflexivity is determined by "indexing one's statements with the point of view one has on its relevant world" (Harré \& van Langenhove, 1999, p. 62). This means that conversation partners' experiences and backgrounds influence their positioning (beliefs, thoughts, judgments), and in turn, their actions (Yoon, 2008). According to Davies and Harré (1990), interactive positioning is "how one person positions another" (p. 48). 
Conversation partners' positioning limits or extends what they can inhibit or provide in terms of speaking forms and actions (Harré \& van Langenhove, 1999). Interactive positioning helps to identify conversation partners' self- and otherdiscourse based on interaction among the partners themselves and international students of diverse backgrounds. Andreouli (2010) asserted that an interactive position emphasizes the other as an integral part of the positioning process. Individuals jointly (re)produce relational meanings so that they may see the world from one position, such as using metaphors, storylines, and concepts that may or may not be relevant to others within the self-other discourse. It explains conversation partners' decision-making about social support, communication styles, and conversation content that positively or negatively influence interactive positions for international students. Interactive positioning helps to identify hierarchical interactions among conflicting values or norms on the part of the college student(s) with and without language barriers. In fact, a conversation partner might reject or accept international students as a function of their positioning (Harré \& Moghaddam, 2003). Some conversation partners are not aware of how to support international students of diverse backgrounds. RoseRedwood and Rose-Redwood (2018) and Thomas et al. (2018) discussed that if domestic students (non conversation partners) only interact with local peers, this isolation must have the effect of limiting cultural literacy as well as diminishing their ability to socially interact with peers from diverse cultural backgrounds in different geographical contexts. Positioning theory is, therefore, a powerful lens to examine how conversation partners position themselves and are positioned in cross-cultural interaction contexts.

\section{METHOD}

\section{Research Design}

The research method involved a descriptive qualitative approach using indepth, semi-structured interviews (Seidman, 1998). The aim of the interviewing method was to solicit students' perspectives about their conversation experiences and to unpack the meaning they ascribed to those experiences. Interviewing is a powerful way to gain insight into the educational and social phenomena experienced by individuals in higher education contexts (Seidman, 1998). Interviews are unique as they allow the researcher "to acquire data not obtainable in any other way" (Gay, 1996, p. 223). In line with that logic, the interviewing method is appropriate for exploring American students' conversational partnership experiences with Chinese international students.

\section{Research Site}

One flagship university, Midwestern University (pseudonym), was the site for this study. We chose this site because there is a large international student population in both year- and semester-long academic exchange programs within 
undergraduate programs. The rationale was to include participants from Midwestern University in the accessible geographical region.

\section{Participants and Sampling}

We used a nomination process (Yin, 2003) to identify participants. It consisted of collecting relevant information about the American conversation partners of international students. The selection of participants involved contacting the university's international education office for nomination of American students matching the selection protocol criteria. The first selection criterion was that all American students must serve as an English-speaking conversation partner of international students, and the second was that they must meet international students and exchange conversations on a weekly basis. In this study, participants were recruited by the lead researcher during the spring semester of 2019. The study was approved by the lead researcher's university's Institutional Review Board. We contact American undergraduate students via email to ask for participants. In this study, we sought prospective participants who agreed to participate and complete two interview sessions during the spring 2019 semester. Seven participants provided permission to use interview data from this study.

Table 1: Participant Demographics

\begin{tabular}{lcccc}
\hline Student & Age & Gender & $\begin{array}{c}\text { Years in the } \\
\text { conversation program }\end{array}$ & Academic major \\
\hline Chuck & 22 & Male & 2 & Mathematics \\
Heather & 22 & Female & 3 & Journalism \\
Izzy & 22 & Female & 2 & Art \\
Kyle & 22 & Male & 2 & Accounting \\
Lisa & 20 & Female & 1 & International Studies \\
Mary & 20 & Female & 2 & Complish \\
Beth & & & & Computer Science \\
Ronnie & 21 & Male & 1 & .
\end{tabular}

Note. All participants were Caucasian and native English speakers.

The participants were seven American undergraduate students (three men and four women) at Midwestern University. All seven participants were born and raised in the Midwest region of the United States. We used pseudonyms to protect the identities of participants. The participants served as conversation partners of Chinese international exchange students every fall semester. Approximately 30 to 40 Chinese international exchange students participated in English as a second language programs and registered for a few academic major courses each fall semester. Each conversation partner was assigned to meet a few Chinese students as one group on a weekly basis. Two participants (Kyle and Chuck) subsequently traveled and participated in a summer program at the Chinese university where their Chinese international exchange student partners attended. 
We purposefully sampled participants using maximum variation sampling (Patton, 2002). All participants were undergraduate students with varying academic status (sophomore through senior), age, gender, location, and types of high schools they had attended, and academic majors (see Table 1).

\section{Data Collection}

\section{Face-to-Face Open-Ended Interviews}

According to Yin (2003), researchers have two jobs in conducting interviews: (a) to follow the interview protocol, and (b) to ask the researcher's actual (conversational) questions. The interviewing researcher asked participants openended questions about factual information as well as their opinions about people, places, and events related to the conversation partnership program. Interviews were face-to-face and lasted approximately 60-90 min. Interviews remained open-ended and assumed a conversational tone. We adapted the interview questions from those in Lewis et al. (2004) and by Sato and Hodge (2009), as their interview questions were well designed to include theoretical framework and research questions. Examples of interview questions included: (a) How have your experiences in communicating with Chinese international students in conversational sessions changed over time? (b) What are the challenges of speaking with Chinese international students in your conversation sessions? Did you use any techniques or strategies for overcoming these challenges? (c) In what ways could your friends or professors (e.g., language faculty) serve your needs and help solve issues and concerns you are facing in communicating Chinese international students in conversational sessions? For this study, we modified specific questions and carefully worded them so as to be relevant to the current investigation of undergraduate students in conversation partnership programs.

\section{Trustworthiness}

Member checking and peer debriefing established trustworthiness. We used member checking to reduce the impact of subjective bias (Patton, 2002). We mailed participants copies of the interview transcripts and themes. Their acknowledgment of the accuracy of the transcripts and of our interpretations of the data ensured that trustworthiness was established (Merriam, 1998). Peer debriefing is a process of exposing oneself to a knowledgeable peer in a manner paralleling an analytic session, with the purpose of exploring aspects of inquiry that might remain only implicit in the inquirer's mind (Patton, 2002). For this study, two professional colleagues who have expertise in qualitative research agreed to serve as peer debriefers. They deemed the interpretations of the data to be accurate and representative of the participants' statements.

\section{Data Analysis}

We used a constant comparative method (Boeije, 2010) to interpret the data. The basic strategy of this analytical process is to constantly compare pieces of 
data while inductively deriving meaning or themes. More specifically, we independently coded the transcripts for themes and then discussed differences until we reached agreement. In addition, two peer debriefers reviewed the codes to avoid potential researcher bias. We compared further coded data from the sets of transcripts from each participant to identify similarities and differences. For example, after peer debriefing, we conducted a second round of coding key terms (e.g., practices, culture, speaking) in the transcripts of data sources (i.e., recoded the original ones). We combined some codes during this process, whereas we split others into subcategories (subthemes). Finally, we examined the final codes to organize them into a hierarchical structure using individual and group coding percentage (how many times key terms appear in the data source). Then we sent back all data and definition of key terms to participants for a second round of member checking. We received final confirmation from all participants and then grouped the codes into thematic categories, which we then refined into recurring themes (Boeije, 2010).

\section{RESULTS}

Four major interrelated and complex themes emerged from the data. They were (a) seeking strategies for overcoming intercultural communication challenges, (b) addressing challenges for explaining sarcasm concepts, (c) finding mutual hobbies and interests, and (d) integrating field trips into the conversation program.

\section{Theme I: Seeking Strategies for Overcoming Intercultural Communication Challenges}

This theme captures that the participants felt that there were differences in communication styles that created challenging situations. The participants perceived that Chinese international students were shy and that participants believed that indirect communication styles were important for implicit understanding of their conversation partners (Banks, 2016). Learning indirect communication styles was an eye-opener for them because they often used direct styles and provided straight messages in order to clarify their intentions. For example, when Kyle (one of the participants) had conversations with Chinese international students in a group setting, he had a hard time understanding what Chinese international students said. He said in the interview that:

When I had a hard time to understand their spoken English, I clearly told them "I do not understand what you said." Then, I realized that the Chinese international students became quiet and were shy and hesitant to talk to me, so I learned it is not about what to say. It is about how to say it. When we were silent, I was not comfortable, because there is an absence of communication during the conversation. I think this is a challenge of intercultural communication.

Kyle believed that it was important that he should be knowledgeable about the cultural differences and find a way to solve intercultural communication issues 
and concerns (Shaules, 2007). Izzy explained that when she found Chinese international students were quiet during the conversation time, she began to think of alternative communication strategies to make the conversation feel more private (e.g., one-on-one communication). For example, she said:

In order to prevent silence and overcome students' shyness, I believe that one-on-one conversation is extremely important, because I would hope that each Chinese international student makes him or herself feel that the conversations are private and they need to practice and improve their spoken English. I scheduled to meet them individually. I am a psychology major and would like to go to an art therapy graduate program in future, so I took each Chinese international student at a different timeframe. One Chinese international student who was very quiet in the group setting, her facial expression changed when I took her to an art museum. We became so close to each other.

Izzy believed that her contact should occur in a variety of contexts with various in-group and out-group members, because she viewed each Chinese international student as an intercultural communication partner rather than a conversation partner.

One of the strategies of overcoming internal cultural communication challenges is that I need to improve my skills in questioning during the conversation. I hoped that I could have flowing conversations, but sometimes it is not happening with Chinese international students. I need to change my mind that it is ok that conversations are not consistent. A conversation partner should support Chinese students to speak English more and help their speaking in English. I strongly believe that developing skills in questioning are important.

She believed that skills in questioning are important, because her questions ask Chinese students to extend and deepen their understanding of the knowledge beyond information. She also mentioned that she used a textbook of teaching English as second language to begin the conversation. She hoped to become a teacher and would like to teach English as second language at public schools. She hoped to see significant changes, improvement, and outcomes during the conversations. Therefore, she began to use various strategies of prompting, clarification, seeking critical awareness, and refocusing questions.

\section{Theme II: Addressing Challenges for Explaining Sarcasm Concepts}

The participants used various verbal and nonverbal ways to express sarcasm during the conversations with Chinese international students, including vowel lengthening, increased articulation, slurred speech, raised eyebrows, and eyerolling. However, Chinese international students had difficulty extracting the meaning of the participants' sarcastic expressions, because the participants' sarcasm employed contradictions between literal and intended meaning. The Chinese international students were positioned in uncomfortable and confused 
situations during the conversation. For example, Chuck often used sarcastic expressions when he talked to Chinese international students. However, they had a hard time understanding the true meaning of his sarcastic expressions. He said:

Chinese international students and I went to one event, to bowling together. All Chinese students knew that I am not good at bowling, but I said that "I am ready to have a perfect score today!!" All the Chinese students looked confused. I am not sure if they understood my sarcastic expressions or not. I realized that I should test whether my sarcastic expressions are working or not.

He found that he needed to be careful about how to use sarcastic expressions, because he learned that the sarcastic expressions might position international students in uncomfortable situations. Izzy also shared and explained another case, saying, "[I told my conversation partner] when the [English as second language] classes make you bored, you don't need to go to school, just call me and I will be your instructor.....it was a joke, but the Chinese international student believed it." Izzy used sarcasm, but the Chinese international students did not catch that it was a joke.

Ronnie explained that there are multiple indicatory cues (e.g., gestures, facial expressions, body movements, personal space) of sarcasm that Chinese international students had difficulty detecting. He said:

I used different types of humor using facial expressions and gestures. Some students gave me weird looks and it seemed that they looked at me as if I am a strange person. I used sarcasm to build friendships, but I thought...I should understand their cultural backgrounds rather than checking their English competency. I also found that I used sarcasm expressions that have multiple meanings, but many Chinese international students had difficulty to analyze the concept.

Lisa explained that the Chinese international students sensed that sarcasm is closely related to irony. Lisa believed that she had to be cautious about when and how to use sarcastic expressions, or else it would turn to unethical behaviors and ruin social relationships with the international students during the conversations.

I have a fear that sarcasm may ruin our relationships because of cultural differences. I learned that sarcasm turned to ironic expressions that are not acceptable in certain cultures. All conversation partners must understand each international student's background and culture before using sarcastic expressions including showing emotions and expressing surprise. I learned one thing from the conversational partnership, that Chinese international students must develop friendships with others before they accept others' sarcastic expressions. This was very interesting.

Lisa found that there are significant influences of cultural and language proficiency on the Chinese international students' ability to appropriately analyze the sarcastic concepts that increase positive social interactions. 


\section{Theme III: Finding Common Hobbies and Interests}

This theme exposed that the participants felt it was important to seek international students' common hobbies and interests to develop their friendships. They thought that their roles and responsibilities were to help the Chinese international students improve their English-speaking competency. However, they began to think that the conversational practice should not only be based on doing specific tasks, but also on international students' social needs. Therefore, they began to seek common hobbies and interests for developing better social relationships. Through their conversations with the international students, they began to seek interactive relationships rather than task-oriented relationships. For example, Heather explained:

When I began conversation practice with international students. I thought that I needed to help their English-speaking proficiency. I was more interested in learning about their personal backgrounds, so I began to seek common hobbies and interests. One student told me that she was a big fan of one musician I liked, so we began to talk about songs and lyrics. I learned about the student more and more. I missed her when she left.

Heather determined the conversational topics in the beginning and initiated the conversation. However, she searched for topics of conversation and mutual interests, so that the Chinese international students could engage in the conversations more. Therefore, she believed that establishing common ground with the Chinese international students was an important feature of great conversations, similar to the findings of Arkoudis et al. (2012), Clark et al. (2019), and Thomas et al. (2018). Ronnie explained:

Three male students and I found a mutual hobby of basketball. I think playing sports was an excellent way to develop mutual understanding, trusting relationships, and social care. When we played basketball together, we tried to find a way to avoid miscommunication during the game. Our motivation was to win the game, so we had common goals of how to play better. After the games, we hanged out and practiced a lot. I am not sure that I was a helpful mentor for them, but for me, they allowed me to become a part of their friends.

Ronnie believed that if social aspects of conversational interaction were absent, he would not be able to find natural conversation or help the Chinese international students to improve their speaking competency (Clark et al., 2019).

\section{Theme IV: Integrating Field Trips into the Conversational Partnership Program}

The participants believed that field trips helped them to think and try various instructional skills and techniques during the conversations with the Chinese international students. During a trip to Washington D.C., the participants were 
assigned to serve as the tour guides for the Chinese international students at various tourist and historical sites. Therefore, the participants not only improved their interpersonal relationships, but also served as cultural mediators who helped translate the culture and history of the United States in order to share information and develop learning relationships (Wilson, 1993). Kyle indicated that the conversation partnership during the field trip was a challenge, but he learned about how to explain the cultural and historical concepts of this country to the Chinese international students. He felt that the field trip was important for the conversation partnership program.

I think the field trip of the conversation partnerships was so important for both American and international students. It is not only about crosscultural understanding, but especially for American students, they learned how to explain and make the international students understand about cultural and historical concepts. We visited many monuments I did not know how to explain... This is very difficult to explain... I think this type of challenge is so important for me.

Kyle believed that the field trip not only increased his knowledge and skills of cultural mediation, but also helped him self-reflect on his own perspectives. Izzy also shared her experiences:

I felt that the field trip was the only way to learn international students' habits. For example, I am Christian, so I pray before having meals, but some of Chinese international students were Buddhists. I learned different religious habits and practices. I have a holy cross pendant. They had Buddhist rosaries and amulets. I felt that the field trip broadened my world views, beliefs, and faith. I felt that there were some topics I was hesitant to ask...but the field trip helped me to gain multicultural understanding toward religions and habits.

Izzy explained that she increased her understanding of global perspectives including open-mindedness and non-prejudiced. She felt that it is important to individualize and respect the Chinese international students, not criticize them based on their beliefs or faith.

\section{DISCUSSION}

Our findings indicate that these American conversation partners gave meaning to four different themes (seeking strategies for overcoming intercultural communication challenges, addressing challenges for explaining sarcasm concepts, finding mutual hobbies and interests, and integrating field trips into the conversational program) in interacting with Chinese international students during their conversations. Their struggles were related to communication barriers, sarcasm concepts, and cultural differences associated with the experiences of international students.

All seven American conversation partners found that when they had English language conversations with Chinese international students, they unintentionally 
positioned some international students outside or in a powerless learning environment, based on the communication barriers. Crawford (2000) explained that international students' accent or use of different expressions could interfere with communication, and American conversation partners were uncomfortable, frustrated, and fearful of international students' shyness during the conversations. Banks (2016) described that American conversation partners explicitly expressed their ideas and clarified their intentions by using direct messages (low-context culture). However, like many other Asian countries, Chinese international students are considered to be collectivists who value interpersonal relationships and close relationships and use indirect messages (high-context culture). American conversation partners must understand that Chinese international students may have situation-specific anxiety (e.g., being shy and quiet) that directly and negatively affects an individual in specific situations (e.g., speaking to conversation partners; Sato \& Hodge, 2015b; Woodrow, 2006).

American conversation partners scheduled individual meetings with their Chinese international student partners and avoided group meetings because they hoped to develop a true cross-cultural friendship. Using positioning theory (Harré \& Moghaddam, 2003), we can explain this as the American conversation partners making choices for improving the conversational quality and finding rationale for their choices. Finally, they began to reflect, assess, and evaluate the consequences of choices for self and others. Therefore, it is important that American conversation partners and Chinese international students experience crosscultural friendships and accept cultural pluralism through the interactions (Wilson, 1993).

These American conversation partners learned that language patterns such as use of sarcasm are understood differently in another language (van Nes et al., 2010). It seems that the conversation partners felt that Chinese international students failed to detect a native speakers' sarcastic cues, because they struggled to capture linguistic accuracy and nuance from conversation partners' sarcastic expressions (J. Kim \& Lantolf, 2018). Polkinghorne (2005) explained that the relation between individuals' experiences and language is a two-way process. Language is used to express meaning. However, language influences how meaning is constructed. Giving words to experience is a complicated process as the meaning of experiences may not be accessible for individuals and may be difficult to express in language. In positioning theory, the conversation partners' social and academic positions were governed by Chinese international students' expectations, definitions, and norms (Hermans, 2001). Therefore, their positions significantly impacted how Chinese international students organized their own learning and oral communication. The conversation partners should focus on intercultural language and communicative practices that emphasize culturally relevant communication (Sato, 2016) so that the Chinese international students find their own style of learning, and possibly gain the ability to understand sarcastic expressions in English.

The current study found that the American conversation partners thought that the conversation experiences with Chinese international students were new, exciting, and fascinating. However, they had difficulties in assimilating to new 
cross-cultural environments. They felt that their language barriers and cultural differences may become prolonged communication obstacles throughout their interactions. That is to say, communication patterns were very different from the American conversation partners (see also Sato \& Hodge, 2015a). These American conversation partners investigated hobbies (e.g., sports) and common interests (e.g., music) from their host country of China to offer social support or mutual understanding with Chinese international students on the university campus. They self-reflected and positioned themselves to seek and support the emotional and academic needs of the Chinese international students (Davies \& Harré, 1990; Tung, 2011). This reflects Thomas et al.'s (2018) suggestion of leveraging common ground to facilitate communication. Nilsson et al. (2008) suggested that student group activities (e.g., playing weekly sports) may offer social bonding opportunities that help Chinese international students feel welcomed, and through participation in conversation sessions they can share information such as the transition into new academic courses and common issues of acculturation stress on an American university campus. The way American conversation partners position themselves and others during conversational practices was important, because their positioning affected the nature of Chinese international students' interactions and their access to learning opportunities. Interactive positioning occurs in the moment of academic and social interaction (Harré \& van Langenhove, 1999), but it is also contextually tied across interaction or scale of conversational activities (Kayi-Aydar, 2013, 2014).

The American conversation partners believed that field trips with the Chinese international students helped them to generate positive perceptions, increase friendships, and improve their conversational speaking skills (Behrendt \& Franklin, 2014). Kolb (1983) explained that field trips are a type of authentic, first-hand, and sensory-based experiential learning. Experiential learning activities involve exploring, touching, listening, watching, moving things, disassembling and reassembling, and learning, and consist of grasping an experience and then transforming it into a result (Kolb, 1983). The American conversation partners sought and partook in field trip opportunities outside the conversation sessions and began to engage in self-directed learning to improve their own conversational skills and techniques (e.g., explaining American history $\&$ culture) at the historical sites such as monuments and museums. They were positioned and motivated to initiate their own self-directed learning, which helped them to make decisions and become responsible for their own learning process. Behrent and Franklin (2014) suggested that field trips play a significant beneficial role in cross-cultural learning. For example, college and university students who have hands-on, authentic experiences develop curiosity and interest about history and culture and are then motivated to learn more. In positioning theory, through these field trip experiences, social skills develop as the students share perceptions and knowledge with others. Students may begin to look forward to classes and connect previous knowledge and experiences with the new concepts. 


\section{Study Limitations}

This study has several limitations. First, the participants were deliberately selected from just one public research university in the Midwest of the United States. Statistically speaking, therefore, the findings are not generalizable. From a qualitative perspective, however, the reader may assume transferability to contexts of colleges or universities elsewhere where there are contextual similarities with conversation partners (Leininger, 1994). Second, the number of participants was small, and this study only focused on American conversation partners of Chinese international students with relatively similar backgrounds and experiences. However, qualitative inquiries typically use small samples, and in the logic of variation sampling, the intent is to capture and describe the central themes that cut across a vast array of participant variation (Patton, 2002). Our intent in using this sampling approach was to uncover common themes reflecting American conversation partners who interacted with Chinese international students. Future studies should investigate conversation partner programs with international students from different national and cultural backgrounds in order to more fully understand the effects of these variables on conversation partner program outcomes. Future research should also include perspectives of both domestic and international students in order to better understand the similarities and differences in their experiences. Future research could also investigate longitudinal changes in experiences over time.

\section{CONCLUSION}

Based on their conversational experiences with Chinese international students, the American conversation partners experienced intercultural communication challenges such as understanding sarcastic expressions. These findings are consistent with previous findings involving conversation partners at U.S. colleges and universities (e.g., J. Kim \& Lantolf, 2018; Wilson, 1993). American colleges and universities still need to do more to promote cultural learning and positive relationship outcomes between conversation partners and international students.

First, offices of international education should include an orientation session on strategies for communicating with international students in conversation partnerships. This echoes a suggestion also made by E. J. Lee (2016). Such an orientation session could address potential interactional and linguistic challenges and dichotomies on campus (e.g., language of ideas and language of display; Bunch, 2009). When American conversation partners communicate with international students, they need to choose either the language of ideas (any language necessary to complete an academic task, regardless of whether it follows academic norms) or the language of display (language for presenting ideas to particular academic audiences in academic contexts) during the conversations. Such an orientation session would be helpful for American conversation partners in developing linguistic and communication resources, seeking opportunities for peer support, and facilitating equal opportunity for international students' participation in group discussions. 
Second, an email partnership program is another possible strategy to support a mood of transnationalism so that American conversation partners and international students may begin to understand each other's cultural, linguistic, and behavioral norms (Guidry Lacina, 2002). This approach allows both international and American students to better understand each other's preferences regarding group versus individual meetings, format, setting, and duration of the conversation so that the conversation partners help answer questions, reduce each other's concerns, and avoid cultural misunderstandings (Yakunina et al., 2011).

Lastly, international sport events and/or movie nights can help promote friendships between the conversation partners and international students (Guidry Lacina, 2002). Such events could be seen as a type of common ground, which Arkoudis et al. (2012) and Thomas et al. (2018) suggested would facilitate interaction between international and domestic students. For example, the conversation partner program could promote awareness of foreign films from around the world and offer inexpensive opportunities for other potential conversation partners as well as the local community. This opportunity may allow the international students to practice English in the local community.

To better support conversation partner programs, we encourage academic departments and faculty to develop a study group for those participating in conversational partnerships to better understand the variety of values, origins, languages, and cultures of participants. This may contribute to a greater appreciation for the richness of diversity and to meaningful academic and social experiences available at American universities for all students.

\section{REFERENCES}

Aaron, R., Cedeno, C., Garies, E., Kumar, L., \& Swaminathan, A. (2018). Peer to peers: Developing a student-coordinated conversation partner program. Journal of International Students, 8(3), 1316-1327.

Abe, J., Talbot, D. M., \& Geelhoed, R. J. (1998). Effects of a peer program on international student adjustment. Journal of College Student Development, 39, 539-547.

Andreouli, E. (2010). Identity, positioning and self-other relations. Papers on Social Representations, 19(1), 14.1-14.13.

Arkoudis, S., Watty, K., Baik, C., Yu, X., Borland, H., Chang, S., Lang, I., Lang, J., \& Pearce, A. (2012). Finding common ground: Enhancing interaction between domestic and international students in higher education. Teaching in Higher Education, 18, 222-235.

Banks, S. (2016). Behind Japanese students' silence in English classroom. Accents Asia, 8(2), 54-75.

Batterton, J., \& Horner, S. L. (2016). Contextual identities: Ethnic and national identities of international and American students. Journal of Studies in International Education, 20(5), 472-487.

Behrendt, M., \& Franklin, T. (2014). A review of research on school field trips and their value in education. International Journal of Environmental and Science Education, 9, 235-245. 
Boeije, H. R. (2010). Analysis in qualitative research. SAGE.

Buhs, E. S. (2005). Peer rejection, negative peer treatment, and school adjustment: Self-concept and classroom engagement as mediating process. Journal of School Psychology, 43(5), 407-424.

Bunch, G. C. (2009). "Going up there": Challenges and opportunities for language minority students during a mainstream classroom speech event. Linguistics \& Education, 20(2), 81-108.

Chang, M. (2011). Helping the international student understand the American university. New Directions for Higher Education, 153, 21-24.

Cheng, R., \& Erben, A. (2011). Language anxiety: Experiences of Chinese graduate students at US higher institutions. Journal of Studies in International Education, 16(5), 477-497.

Clark, L., Pantidi, N., Cooney, O., Doyle, P., Garaialde, D., Edwards, J., Spillane, B., Murad, C., Munteanu, C., Wade, V., \& Cowan, B. R. (2019). What makes a good conversation? Challenges in designing truly conversational agents. The 2019 ACM CHI Conference on Human Factors in Computing Systems. doi:10.1145/3290605.3300705

Crawford, J. (2000). At war with diversity: US language policy in an age of anxiety. Multilingual Matters.

Davies, B., \& Harré, R. (1990). Positioning: The discursive production of selves. Journal for the Theory of Social Behaviour, 20, 43-63.

Gay, L. R. (1996). Educational research: Competencies for analysis and application (5th ed.). Prentice-Hall.

Geary, D. (2016). How do we get people to interact? International students and the American experience. Journal of International Students, 6, 527-541.

Geelhoed, R. J., Abe, J., \& Talbot, D. M. (2003). A qualitative investigation of U.S. students' experiences in an international peer program. Journal of College Student Development, 44, 5-17.

Guidry Lacina, J. (2002). Preparing international students for successful social experience in higher education. New Directions for Higher Education, 117, 21-28.

Hamm, J. V., \& Zhang, L. (2010). The schooling context of adolescents' peer relations. In J. Meece \& J. Eccles (Eds.), The handbook of schools and schooling effects on development (pp. 518-554). Erlbaum.

Harré, R., \& Moghaddam, F. M. (Eds.). (2003). The self and others: Positioning individuals and groups in personal, political and cultural contexts. Praeger.

Harré, R., \& van Langenhove, L. (1999). The dynamics of social episodes. In R. Harré \& L. van Langenhove (Eds.), Positioning theory: Moral contexts of intentional action (pp. 1-13). Blackwell.

Hermans, H. J. M. (2001). The dialogical self: Toward a theory of personal and cultural positioning. Culture \& Psychology, 7(3), 243-281.

Hollway, W. (1984). Gender difference and the production of subjectivity. In J. Henriques, W. Hollway, C. Urwin, C. Venn, \& V. Walkerdine (Eds.), Changing the subject: Psychology, social regulation and subjectivity (pp. 227-263). Methuen. 
Institute of International Education. (2019). Open Doors: Report on international educational exchange. Retrieved December 11, 2019 from $\mathrm{http}: / /$ www.iie.org/opendoors.

Jones, R. A. (1997). Direct perception and symbol forming in positioning. Journal for the Theory of Social Behaviour, 29, 37-58.

Kayi-Aydar, H. (2013). Scaffolding language learning in an academic ESL classroom. ELT Journal, 67(3), 324-335.

Kayi-Aydar, H. (2014). Social positioning, participation, and second language learning: Talkative students in academic ESL classroom. TESOL Quarterly, 48, 686-714.

Kim, D., Pan, Y., \& Park, H. S. (1998). High- versus low-context culture: a comparison of Chinese, Korean, and American cultures. Psychology \& Marketing, 15, 507-521.

Kim, J., \& Lantolf, J. P. (2018). Developing conceptual understanding of sarcasm in L2 English through explicit instruction. Language Teaching Research, 22, 208-229.

Kolb, D. (1983). Experiential learning, experiences as the source of learning and development. Prentice Hall.

Ladd, G. W., Herald-Brown, S. L., \& Kochel, K. P. (2009). Peers and motivation. In K. R. Wentzel \& A. Wigfield (Eds.), Handbook of motivation at school (pp. 323-348). Routledge.

Lee, E. J. (2016). International and American students' perceptions of informal English conversations. Journal of International Students, 6, 14-34.

Lee, J. J., \& Rice, C. (2007). Welcome to America? International student perceptions of discrimination. Higher Education, 53(3), 381-409.

Leininger, M. (1994). Evaluation criteria and critique of qualitative research studies. In J. M. Morse (Ed.), Critical issues in qualitative research methods (pp. 95-115). SAGE.

Leong, F. T. L., \& Chou, E. L. (1996). Counseling international students. In P. B. Pedersen, J. G. Draguns, W. J. Lonner, \& J. E. Trimble (Eds.), Counseling across cultures (pp. 210-242). SAGE.

Lewis, C., Ginsberg, R., Davis, T., \& Smith, K. (2004). The experiences of African American $\mathrm{PhD}$ students at a predominantly White Carnegie Iresearch institution. College Student Journal, 38(2), 231-245.

Li, X., \& Chen, W. (2014). Facebook or Renren? A comparative study of social networking sit use and social capital among Chinese international students in the United States. Computers in Human Behavior, 35, 116-123.

Luo, J., \& Jamieson-Drake, D. (2013). Examining the educational benefits of interacting with international students. Journal of International Students, 3, $85-101$.

Merriam, S. B. (1998). Qualitative research and case study applications in education. Jossey-Bass.

Nilsson, J. E., Butler, J. Shouse, S., \& Joshi, C. (2008). The relationship among perfectionism, acculturation, and stress in Asian international students. Journal of College Counseling, 11, 147-158. 
Nishioka, H. (2014). Activating the Zone of Proximal Development of Japanese language learners: Language-exchange partnerships (LEPs) at an Australian university. New Voices, 6, 145-171.

Patton, M. Q. (2002). Qualitative research and evaluation methods (3rd ed.). SAGE.

Pedersen, P. B. (1991). Counseling international students. The Counseling Psychologist, 19, 10-58.

Polkinghorne, D. (2005). Language and meaning: Data collection in qualitative research. Journal of Counseling Psychology, 52, 137-145.

Rose-Redwood, C., \& Rose-Redwood, R. (2018). Building bridges across the international divide: Fostering meaningful cross-cultural interactions between domestic and international students. Journal of International Students, 8(3), 1328-1336.

Ruble, R. A., \& Zhang, Y. B. (2013). Stereotypes of Chinese international students held by Americans. International Journal of Intercultural Relations, 37, 202-211.

Ryan, J., \& Hellmundt, S. (2005). Maximizing international students' cultural capital. In J. Carroll \& J. Ryan (Eds.), Teaching international students: Improving learning for all. Routledge.

Ryan, J., \& Viete, R. (2009). Respectful interactions: Learning with international students in the English-speaking academy. Teaching in Higher Education, 14(3), 303-314.

Sato, T. (2016). Doctoral sojourn experiences of adapted physical education students from Asian countries. Journal of International Students, 6(2), 339366.

Sato, T., \& Hodge, S. R. (2009). Asian international doctoral students' experiences at two American university: Assimilation, accommodation, and resistance. Journal of Diversity in Higher Education, 2(3), 136-148.

Sato, T., \& Hodge. S. R. (2015a). Academic and social experiences of exchange students from Japan attending an American university. College Student Journal, 49(1), 78-92.

Sato, T., \& Hodge, S. R. (2015b). Japanese exchange students' academic and social struggles at an American university. Journal of International Students, 5(3), 208-227.

Seidman, I. (1998). Interviewing as qualitative research: A guide for researchers in education and the social sciences ( 2 nd ed.). Teacher College Press.

Shaules, J. (2007). Deep culture: The hidden challenges of global living. Multilingual Matters.

Sheets, R. H. (2005). Diversity pedagogy: Examining the role of culture in the teaching-learning process. Pearson Education.

Spencer-Rodgers, J. (2001). Consensual and individual stereotypic beliefs about international students among American host nationals. International Journal of Intercultural Relations, 25(6), 639-657.

Spitzman, E., \& Waugh, M. (2018). Structured and critical intercultural programming: Faculty and staff collaborate to put research into action. Journal of International Students, 8, 1337-1345. 
Thomas, V. F., Ssendikaddiwa, J. M., Mroz, M., Lockyer, K., Kosarzova, K., \& Hanna, C. (2018). Leveraging common ground: Improving international and domestic students' interaction through mutual engagement. Journal of International Students, 8(3), 1386-1397.

Tung, W.-C. (2011). Cultural barriers to mental health services among Asian Americans. Home Health Care Management \& Practices, 23(4), 303-305.

Ursell, E. F. (2014). Conversation partners in the writing center. Praxis: A Writing Center Journal, 11, 1-6.

van Nes, F., Abma, T., Jonsson, H., \& Deeg, D. (2010). Language differences in qualitative research: Is meaning lost in translation? European Journal of Ageing, 7, 313-316.

Vanassche, E., \& Kelchtermans, G. (2014). Teacher educators' professionalism in practice: Positioning theory and personal interpretative framework. Teaching and Teacher Education, 44, 117-127.

Varela, C., \& Harré, R. (1996). Conflicting varieties of realism: Causal powers and the problems of social structure. Journal for the Theory of Social Behaviour, 26, 313-325.

Welikala, T., \& Watkins, C. (2008). Improving intercultural learning experiences in higher education: Responding to cultural scripts for learning. Institute of Education, University of London.

Wilson, A. H. (1993). Conversation partners: Helping students gain a global perspective through cross-cultural experiences. Theory into Practice, 32(1), $21-26$.

Woodrow, L. (2006). Anxiety and speaking English as a second language. Regional Language Center Journal, 37(3), 308-332.

Yakunina, E. S., Weigold, I. K., \& McCarthy, A. S. (2011). Group counseling with international students: Practical, ethical, and cultural considerations. Journal of College Student Psychotherapy, 25, 67-78.

Yin, R. K. (2003). Case study research design and methods (3rd ed.). SAGE.

Yoon, B. (2008). Uninvited guests: The influence of teachers' roles and pedagogies on the positioning of English language learners in the regular classroom. American Educational Research Journal, 45, 495-522.

Zhang-Wu, Q. (2018). Chinese international students' experiences in American higher education institutes: A critical review of the literature. Journal of International Students, 8, 1173-1197.

TAKAHIRO SATO, PhD, CAPE, is a professor and chair of the joint master's program in International Development and Peace through Sport at the University of Tsukuba, Ibaraki, Japan. His scholarship and research focus is on Japanese education, multicultural physical education, disability studies, adapted physical education professional development, and diversity in higher education. Email: sato.takahiro.gf@u.tsukuba.ac.jp 
RYAN MILLER, $\mathrm{PhD}$, is an associate professor in the TESL program at Kent State University, Ohio, USA. His research focuses on second language (L2) reading and writing. Within $\mathrm{L} 2$ reading, he investigates how reading and reading subskills (e.g., morphological awareness, phonological awareness, lexical inferencing ability) developed in a first language can support reading in a second language. Within L2 writing, he researches development of disciplinary genre knowledge using the tools of systemic functional linguistics. Email: rmill129@kent.edu 